\title{
EMERGENCY PREPAREDNESS PLAN IN EDUCATIONAL INSTITUTION
}

\author{
R. Gowtham Kumar ${ }^{1}$, T.Dheenathayalan ${ }^{2}$ \\ ${ }^{I}$ PG Scholar, Department of Mechanical Engineering, Knowledge Institute of Technology, Tamilnadu, India \\ ${ }^{2}$ Assistant Professor, Department of Mechanical Engineering, Knowledge Institute of Technology, Tamilnadu, India
}

\begin{abstract}
Emergency planning is important to prevent accidents in handling of hazardous chemicals, handling of heavy machines, electrical supplies and natural disasters which affect the environment and the community negatively and taking necessary steps to prevent the impacts. The facilities available in the institutions are studied and analysed. After the complete study of the emergency plan in the institutions suggestions were given to improve the safety systems. The emergency exit layout was designed and implemented in the laboratories. The entry in and exit design were prepared and executed in the laboratories to escape during the emergency conditions. To prepare emergency plan the details were collected during the handling of heavy machines, hazardous chemicals, and electrical supplies in the institution laboratories.
\end{abstract}

Keywords: Emergency planning, Hazardous chemicals, Heavy machines, Electrical supply.

\section{INTRODUCTION}

An emergency is serious issue which leads to incidents or accidents to cause major/minor problems. Sometimes it may cause major problems to person, machines and to working environment. It is very important to prepare emergency plan for every institutions to create emergency plan for ensuring the safe environment by identifying and avoiding risks. Regular safety rules and guidelines should be given to students before the commencement of laboratory session. List of rules and regulations should be displayed in the laboratory. The emergency plan should be based on the rules and regulations. The trained persons should conduct a regular demo before the execution of the machines. The proper emergency plan and sign boards should be marked in the laboratory for entry and exit. The emergency plan layout in the laboratories should be clear, easily understandable to avoid confusions during the emergency conditions. The risks and problems should identified by collecting information from laboratory in charges. The problems identified and analyzed in the industry should be helpful during the emergency planning and others like health, environmental problems.

George M Rusch (1993) proposed the history and development of emergency response planning guidelines. The Emergency Response Planning guideline committee was formed to review a series of documents summarizing chemical toxicity which has been developed by a combined inter industry effort. This committee is a part of the American Industrial Hygiene Association and is composed of representatives from academia, government and industry, with background in industrial hygiene, medicine and toxicology since its founding, the committee has published 35 review documents containing recommendations for emergency exposure planning levels. Currently, the committee is working on another 25 . Where chemicals are involved it is important to know the identity of the chemical; the toxicity of the chemical and the amount used or stored at the plant. It is also important to have an idea of the area that could be affected if the chemical is accidentally released, and to have an understanding of air flow patterns around the area. With this information local emergency response teams can make estimates of disperse in the event of catastrophic release and make appropriate plans for evacuation of the local community, if necessary. Much of this information should be well known to the plant safety personnel, especially current information on protective equipment, monitoring, respirator selection, and containment practices. There are many guides which offer recommendations for maximum permissible exposure levels for a variety of chemicals.

Hema Prabha.R and Karthikeyan.N proposed the paper on Emergency preparedness in a Dairy Industry. The facilities available in the plant and the state of emergency preparedness followed in the dairy industry is studied and analyzed. The emergency preparedness followed in the dairy industry recommendations are given with an aim to improve the safety system and to incorporate the enhanced technology of emergency preparedness. An attempt to prepare Emergency Plan is done for the facility and the emergency steps to be taken for hazardous chemicals used in the dairy industry are done with the help of information provided in the material safety data sheet and also preparedness in case of fire, water supply interruptions, electrical supply interruptions, sewage backups etc. are suggested. The main reasons for reviewing these plans are: To minimize work efforts by building upon or modifying existing emergency planning and response information and, To ensure proper coordination with other related plans. The main aim of emergency preparedness in an industry is to develop and apply new and existing methodologies and technologies to assist the management in responding to 
emergency situation and to respond well in case of such situations. The author has conducted the mock drill and verified the safety systems, safety signs, electrical and water supply interruptions followed in the industry and gave suggestions to improve the safety technology [2].

\section{METHODOLOGY}

This focus on the emergency planning needed for an institution and establishing a team that could assist the management to be well prepared for an emergency situation and easily handling of those emergency situation. An emergency action plan should be prepared in advance and it will be useful to respond if an emergency occurs. The emergency planning also involves identifying the hazardous chemicals used in the laboratory and the effects that will occur on leakage or spillage or release of those hazardous gases and safety measures, first aid to be provided in case of such emergency situation must be planned well in advance to avoid human losses. To check the efficiency of the plan regular inspection should be made in the laboratories. The emergency planning is prepared based on the layout of the laboratory. The planning gives the solution for emergency exit, way in and out, first aid box, fire extinguisher and safety signs. The safety system used should be based on latest technology

\section{ANALYSIS AND DISCUSSION}
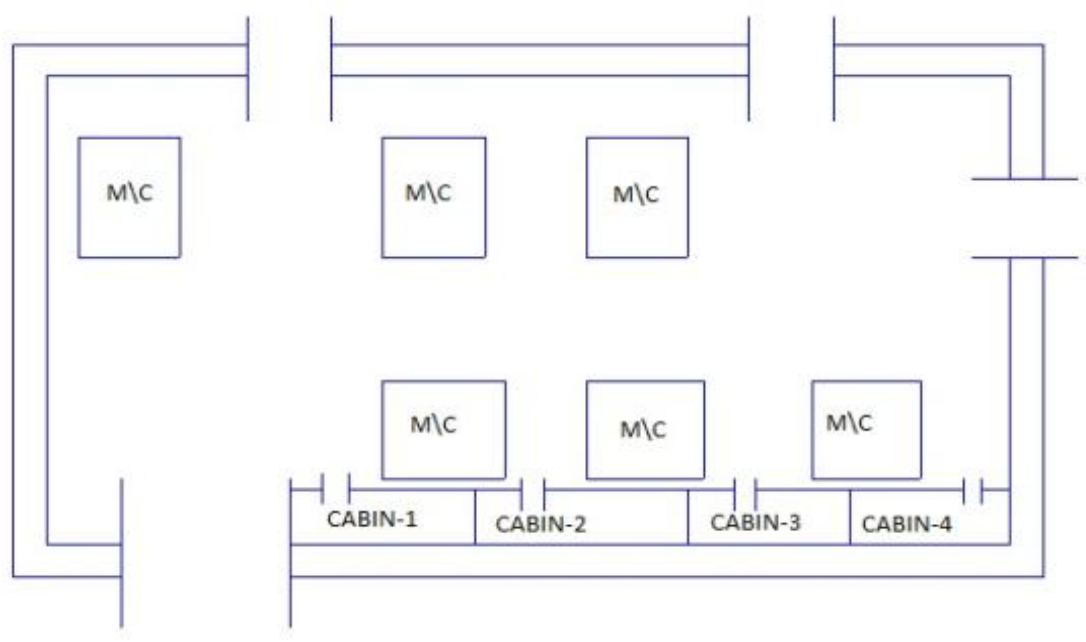

Fig 1(a)
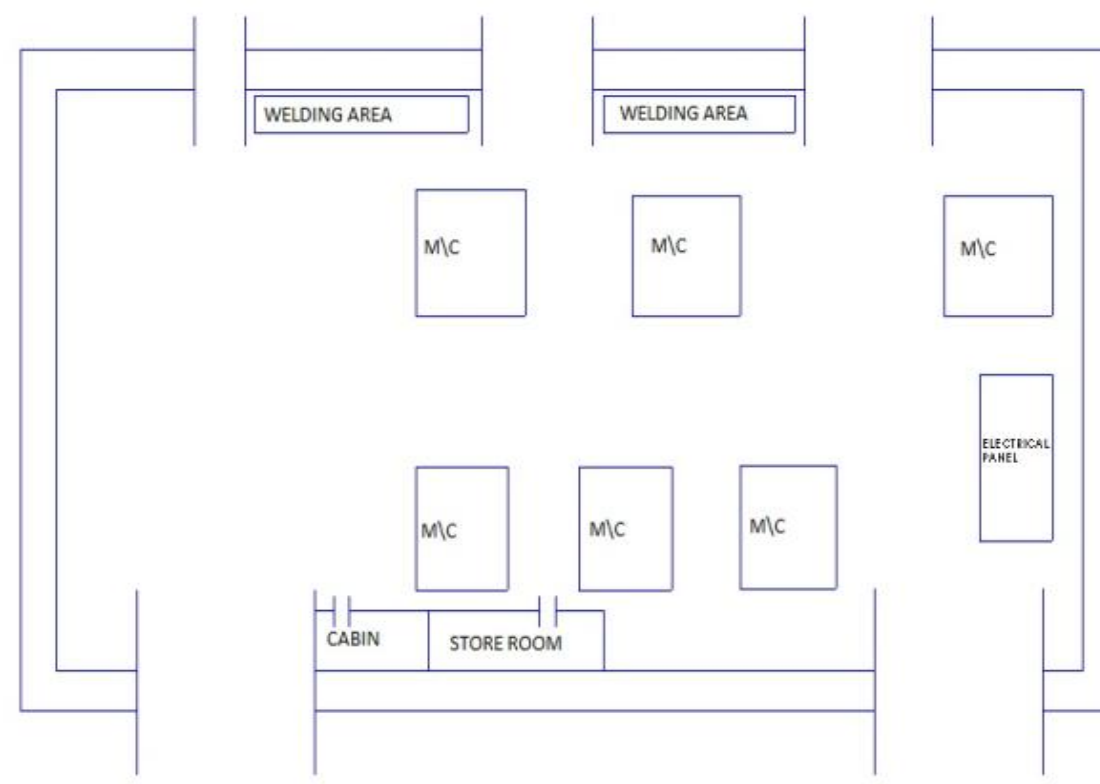

Fig 1(b) 
Figure 1(a) and figure 1(b) is the actual layout of the laboratory. The fig 1(a) has the machine which is placed at the side of the laboratory. The cabin is placed at another side of the laboratory. The laboratory has the entry in and out on the both side of the usage area. The fig 1(b) has the machines placed in the center area and welding area is placed at the side of the laboratory. The both laboratory handles heavy machines. The layout is prepared using the solid works software and the normal plant layout was drawn.

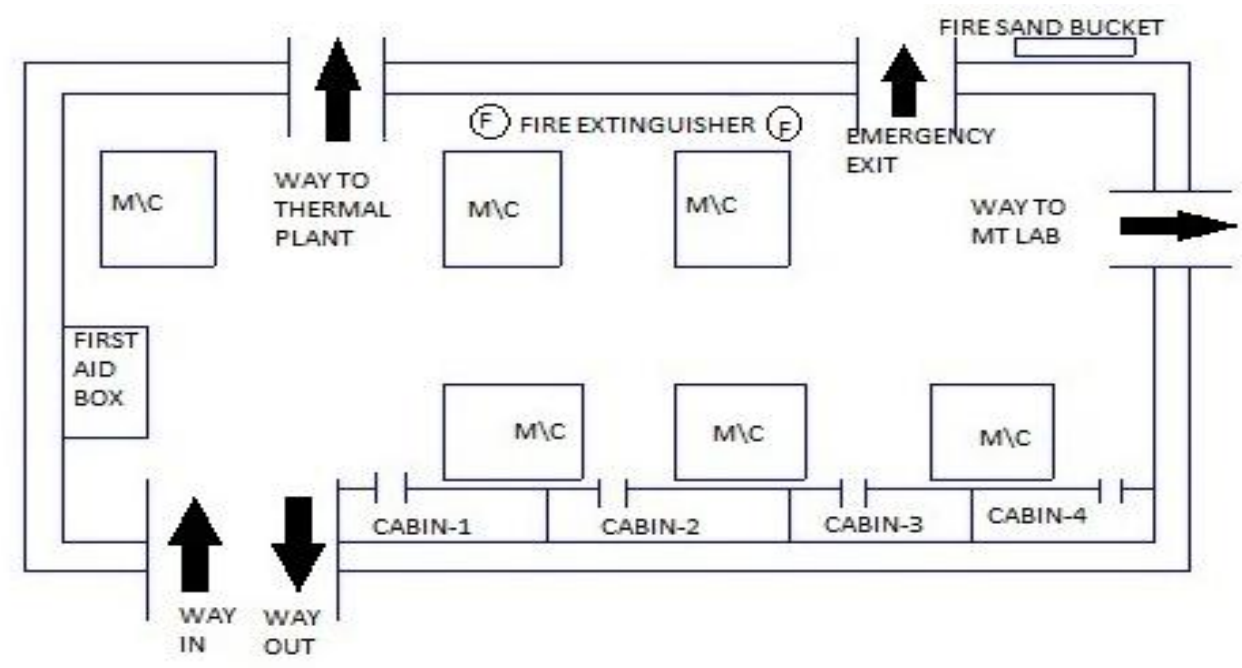

Fig 2(a)

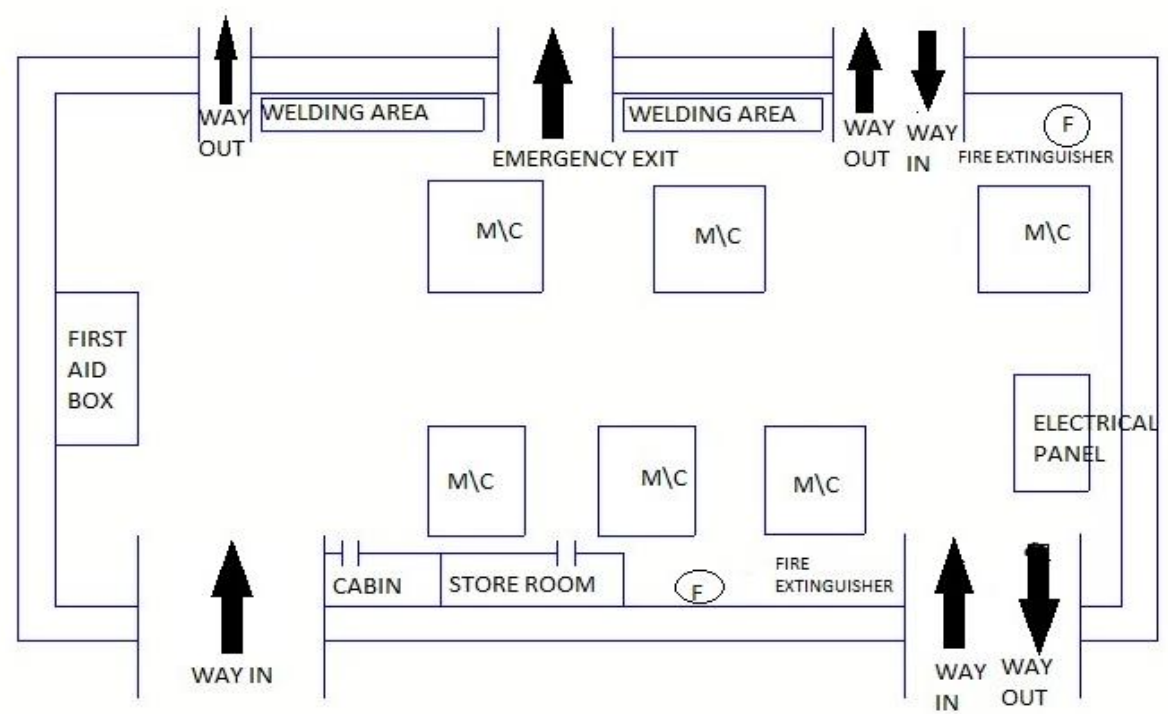

Fig 2(b)

The figure 2(a) and figure 2(b) shows the emergency preparedness in the laboratory. The emergency plan has emergency exit to escape during emergency. The entry in and out is placed and marked separately. The pathways are marked with arrows with a proper ANSI standard. The first aid box and fire extinguisher is marked and placed in the main area of the laboratory

\subsection{Safety Systems}

The safety system followed in the laboratory includes first aid box details, emergency exit, fire sand bucket, personal protective equipment and fire extinguisher.

\subsubsection{First Aid Box}

The first aid box is important to place in the laboratory to treat in the emergency conditions. It is placed in the laboratory with a proper first aid kit. The box will be monitored regularly to check the expiry date.

\subsubsection{Fire Sand Bucket}

It is important to keep fire sand bucket near every place of hazardous material, if the fire occurs it can be easily prevented with help of fire sand bucket. It helps to control fire on time. This is the simplest and quickest way of putting 
off fire. It is recommended that a steel bucket is used. If a plastic bucket is used, it may easily damage, or melt. The bucket should be well marked. The sand must also be cleaned of all flammable material. The sand must be completely dry in the bucket or else the intense heat of the burning metal will quickly flash the moisture into steam.

\subsubsection{Fire Extinguisher}

The fire extinguisher is placed in an open space. The fire extinguishers are hanged in a wall to identify easily and it is placed in a center of the wall to handle easily during emergency. The filling and expiry date is marked in the extinguisher.

\subsubsection{Fire Prevention}

Prevention is always important to avoid major accidents and to prevent loss of life and equipments. For improving safety recent fire preventing techniques should be used.

\subsubsection{Emergency Respond}

The emergency respond helps to avoid accidents and losses. The plan should be prepared based on the site plan and it should be displayed. Emergency responder like emergency exit, fire protecting equipments, medicines to be used in emergency.

\subsubsection{Emergency Exit}

The emergency exit should be designed in the plan to avoid accidents. The emergency exit is marked in the laboratory to escape during emergency conditions. The emergency exit is placed separately from the main entrance.

\subsubsection{Personal Protective Equipment}

Personal Protective Equipment helps to protect the user from the body injury. PPE reduce the exposure of the user from defects. It does not eliminate the hazard but it helps to reduce the impact of the hazard. It strains the user who wears it and reduces the ability of their work being carried out. Good ergonomic condition design of PPE reduces discomfort.

\subsubsection{Safety Sign}

ANSI Z535-2007 standard uses a ratio of 25 feet of viewing distance per inch of text for Favorable Reading Conditions and a ratio of 12 feet of viewing distance per inch of text for Unfavorable Reading Conditions. A common language is used to display safety signs. The safety signs are mounted in the walls.

\section{CONCLUSIONS}

The study results were obtained through the site map of the laboratory. Based on the plan the emergency preparedness was designed and suggestion was given to the institution. Various references were taken from industry and based on that emergency layout was prepared. Based on the findings in the laboratories suggestions were given for emergency exit, personal protective equipments, fire sand bucket first aid box and fire extinguishers. The safety sign and emergency exit is placed in the laboratory. The emergency exit is designed in a separate way. Implementations of these recommendations will be helpful to avoid emergency situations. It helps to avoid accidents during emergencies.

\section{REFERENCES}

[1]. George, M. Rusch (1993) "The History and Development of Emergency Response Planning Guidelines $^{\text {ee }}$ Elsevier Science Publishers B.V., Amsterdam, Vol.33, pp.193-202.

[2]. Hema Prabha.R and Karthikeyan.N (2013)" Emergency Preparedness in Diary Industry", International Journal of Advanced Research (2013), Volume 1, Issue 3, 166-174.

[3]. Chen Chen, Zhang Xin-mei (2012) "Completeness Assessment of Emergency System - Engineering Application in a Petrochemical Reservoir”, Elsevier Science Publishers, Systems Engineering Procedia 5 ( 2012) 144 149. 